\title{
University Budget Models and Indirect Costs: A Primer
}

Jane Radecki 


\section{ITHAKA S+R}

Ithaka $\mathrm{S}+\mathrm{R}$ provides research and strategic guidance to help the academic and cultural communities serve the public good and navigate economic, demographic, and technological change. Ithaka $\mathrm{S}+\mathrm{R}$ is part of ITHAKA, a not-for-profit organization that works to advance and preserve knowledge and to improve teaching and learning through the use of digital technologies. Artstor, JSTOR, and Portico are also part of ITHAKA.

Copyright 2021 ITHAKA. This work is licensed under a Creative Commons Attribution 4.0 International License. To view a copy of the license, please see https://creativecommons.org/licenses/by/4.0/.

ITHAKA is interested in disseminating this brief as widely as possible. Please contact us with any questions about using the report: research@ithaka.org. 


\section{"The significance of a budget to the university cannot be overstated. Through the budgeting process, an institution aligns its resources with its priorities, bringing together income and expenses." -Dean O. Smith ${ }^{1}$}

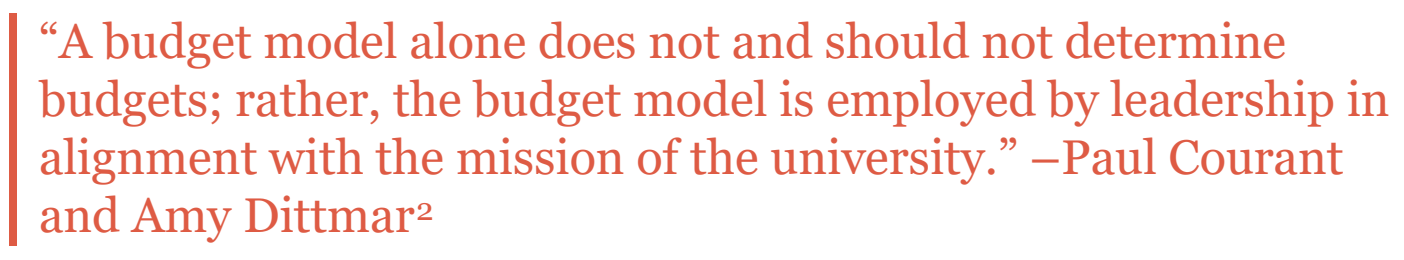

Budgets do not only pay the costs of activities. They also reveal the ambitions and limitations of an organization. The opportunities presented in a budget are also bounded by the structural elements used by that institution: how costs and revenues are organized, how overhead is calculated and apportioned, and how assets and investments are calculated and utilized, among others. In the higher education sector in the US, there are many common budgeting elements but also several important areas of differentiation. This issue brief provides a summary of two important elements of academic budgeting at large research universities and for externally funded research: budget models and indirect costs. ${ }^{3}$

\section{Budget Models}

University budget models can fall within a broad spectrum of options. Terms such as responsibility center management (RCM), activity based budgeting (ABB), and incremental budgeting all refer to an array of methods for allocating revenues and costs within a university system. It should be noted however that few, if any, institutions have a "pure" budget model, rather most universities use a hybrid model where they implement a range of allocation methods for different kinds of revenues and costs. For example, the University of Michigan's website describes how "the U-M budget model functions within a hybrid system of responsibility center budgeting, incremental budgeting, and centralized/initiative budgeting. This mix of budgeting allows the University's leadership to see clearly the fiscal implications of the activities at the school/college/research unit level, while allowing considerable flexibility to set priorities and adjust to fiscal circumstances in light of the University's mission." 4 While most institutions

\footnotetext{
${ }^{1}$ Dean O. Smith, "Budgets," in University Finances: Accounting and Budgeting Principles for Higher Education (Baltimore, MD: Johns Hopkins University Press, 2019), 167.

${ }^{2}$ Paul Courant and Amy Dittmar, "Report on the State of the Budget Model and Budget System at the University of Michigan (Abridged Version)," Review of the University Budget Model undertaken in FY19, 2019, https://obp.umich.edu/wpcontent/uploads/pubdata/budget/Budget\%20Model\%20Review\%20abridged FINAL.pdf.

${ }^{3}$ Ithaka $\mathrm{S}+\mathrm{R}$ is publishing in parallel an examination of the state of academic research budgets today. Jane Radecki and Roger C. Schonfeld, "Academic Research Budgets: A Look Ahead with Special Emphasis on Research Enablement and Support, Ithaka S+R, February 25, 2021, https://doi.org/10.18665/sr.314860.

${ }^{4}$ University of Michigan, "Budget Model and System," Office of Budget and Planning, 2020, https://obp.umich.edu/budget/budgetmodel/.
} 
run on a hybrid model they tend to have one budget model that makes up the majority share and dictates how revenues and expenses are allocated.

Though there are a number of different budget models across US universities, they fall into two basic categories. One is a centralized budgeting process, generally controlled by the provost but sometimes by the CFO. The second is a decentralized budget model in which each of the schools within a university controls their own expenditures and pays to fund university central operations. Even centralized budget models often treat one or two units as "tubs on their own bottom"-for example, the health sciences. In order from more centralized to more decentralized they are as follows: (1) incremental budgeting, (2) zero-based budgeting, (3) performance-based budgeting, (4) activity-based budgeting (ABB), and (5) responsibility center management (RCM) budgeting. Dean O. Smith has provided a useful overview and categorization of this array of budget models, from which the below section draws. 5

\section{Centralized Models}

Some models are centralized in pooling all revenues together centrally to the greatest extent possible. As a result, tuition revenues attributed to the various schools and degree programs, state appropriations, indirect costs (see below), and a variety of ancillary revenues are brought together in a central pool. The university then centrally determines how best to apportion these to subsidiary units and expenditure categories. There are two main approaches to this apportionment.

Incremental budgeting is a widely used model in which the budget for the current fiscal year becomes the base for the next fiscal year. Funding increments are then added to (or subtracted from) the previous year's budget. In this model the next year's budget heavily depends on the previous year's budget. This type of budgeting has historically been appealing to US higher education institutions because it is relatively easy to implement and provides budgetary stability. It assumes that goals and objectives do not change significantly from the current year to the next, and as a result enables institutions and their subsidiary units to plan multiple years into the future with a great deal of stability. One of the drawbacks of this model is that it is limited in its vision. Additionally, it can be difficult to determine where all costs were incurred and how these costs are contributing to further revenue and value creation. ${ }^{6}$ This model thereby provides limited accountability for yearly expenditures, and it does not reflect changing institutional priorities very well. Finally, a significant disadvantage of this model is that it can “discourage careful analysis of the budget units' past performance, thus perpetuating past expenditure outlays into the future."7

\footnotetext{
${ }^{5}$ Dean O. Smith, "Budget Models," in How University Budgets Work (Baltimore: Johns Hopkins University Press, 2019$), 49$.

${ }^{6}$ Hanover Research, "6 Alternative Budget Models for Colleges and Universities," Hanover Research, April 19, 2013, https://www.hanoverresearch.com/insights-blog/6-alternative-budget-models-for-colleges-and-universities/.

${ }^{7}$ Dean O. Smith, 52.
} 
Zero-based budgeting is also a centralized model, requiring that "each unit must justify from the ground up all of its proposed expenditures." 8 At the beginning of every budgetary planning period, the previous year's budget for each unit within the university structure is cleared and wiped away. Every unit must then re-request funding, and all revenue spending must then be rejustified and approved. This model, on the one hand, can be seen as an effective way of eliminating unnecessary costs and focusing on areas of current and emergent strategic priority. In this sense, it is responsive to current revenue performance needs. ${ }^{9}$ On the other hand zerobased budgets require a significant amount of time and labor from units and university administrators to prepare, ${ }^{10}$ and this model can seriously encumber long-term planning. As a result, "academic institutions seldom adhere to a zero-based budget model."11

\section{Performance-Based Budgeting}

Simply put, like its name, performance-based budgeting awards funds based on performance, relative to quantitatively established benchmarks. ${ }^{12}$ It is a budgeting system more based on outcomes than inputs. For higher education this essentially means basing funding and budgeting decisions on outcomes like graduation and retention rates rather than purely on inputs such as the total number of students enrolled. One of the benefits of performance based budgeting is that through the evaluation of performance against designated benchmarks it can force higher education leaders to be more intentional in the way that their university determines what they truly value while at the same time being held more accountable for their university's results.

Seen more commonly in public universities, this model is used when states or individual university leaders demand greater accountability. ${ }^{13}$ This model can give an institution a better idea of how money is expected to translate into results, it increases transparency, and can incentivize specific behaviors. However, budgeting done in this manner requires timeconsuming performance reviews and analysis of performance against expectations. Only after these thorough performance evaluations have been completed can funds be allocated.

\footnotetext{
${ }^{8}$ Dean O. Smith, 48.

${ }^{9}$ Since departments, divisions, and units do not automatically receive a certain sum of revenue each year, as in some budgetary models, each dollar allocated to a unit within the university thereby can be seen as having a purpose, which aids in keeping discretionary spending to a minimum.

${ }^{10}$ Cate Auerbach and Lauren Edmonds, "Exploring Alternative Budget Models," Custom Research Brief, Education Advisory Board (EAB), 2013, https://www.kpu.ca/sites/default/files/President/Exploring-Alternative-Budget-Models.pdf.

${ }^{11}$ Dean O. Smith, 49.

12 Paul Lendway, "How Higher Education Can Practice Better Budgeting," Fels Institute of Government University of Pennsylvania, August 11, 2017, https://www.fels.upenn.edu/recap/posts/1162.

13 Hanover Research, "6 Alternative Budget Models for Colleges and Universities," Hanover Research, April 19, 2013, https://www.hanoverresearch.com/insights-blog/6-alternative-budget-models-for-colleges-and-universities/.
} 


\section{Distributed Revenue Control}

In two models, responsibility for the control of spending is distributed to subsidiary units such as the college, school, or department. These budget centers then determine how best to spend the funds associated with the revenue (such as tuition, student fees, auxiliary fees, and grants and contracts) that they each generate. By distributing responsibility for spending, these models provide much more "on the ground" authority for determining how best to spend resources to achieve the objectives of that unit. One complication of these models is how to handle central expenditures, including central university expenditures such as legal, finance, the president's office, and shared research infrastructure and enablement as well as any cross-subsidization of departments and colleges that are unable to break even.

Activity-Based Budgeting (ABB) provides that the revenue generated by a specific budget unit is allocated back to said unit. To fund central expenses, the university usually imposes a "tax" on the revenue. As a result, budget units receive only a portion of the total revenue which they have generated. The provost uses this tax to supplement other revenue to fund centrally provided institutional infrastructure, strategic investments, special programmatic priorities, other indirect costs, and shared expenses that otherwise would have no direct source of funds.

Responsibility Center Management (RCM) differs from ABB in how responsibility for revenue generation is assigned and how central expenditures are funded, and RCM is the most decentralized budget model. In RCM, each budget unit in the university organizational hierarchy is considered a "responsibility center": responsible not just for managing its own spending but also for generating its own revenues. This type of model can provide an incentive for deans and even chairs to find creative ways to generate additional revenue: "Scholars have suggested that RCM incents academic units to critically assess their offerings against other campus units and other institutions...the pandemic has created an opportunity for such an evaluation across universities - not only in what they offer, but also through what models." 14 Under this model, units generate revenue, cover direct and indirect costs, retain surpluses, and are responsible for their losses; because of this " $\mathrm{RCM}$ has been viewed by practitioners as more flexible than the centralized approach." 15 One of the characteristic differences in an RCM model, as compared to other centrally controlled budget models, is that it allows schools/colleges/research units to carry forward capital surpluses that then can serve as reserves. In a normal year these reserves can be used to expand programs, recruit faculty, and even fund research projects. Unlike other budget models the central university administration does not pay for central services. Instead, each budget unit determines, through a process of negotiation, the extent to which it values the centrally provided services and the amount it is willing to pay for those services. In practice, a formula is usually developed to determine which budget units will pay for what portion of the central costs. This model intentionally produces downward pressure on central expenditures. The RCM budget model can produce competition

\footnotetext{
14 Steffon Gray, "Responsibility Center Management and the COVID-19 Pandemic", NACUBO, July 3, 2020, https://www.nacubo.org/-/media/Documents/Publications/RCM-and-the-COVID-19-PandemicFinal.ashx?la=en\&hash=FA9E9F540A34902EAFDB1597681D69ADB145016C.

${ }^{15}$ Ibid.
} 
between budget units within a university structure for revenue which can thereby run the risk of undermining overall institutional integrity. ${ }^{16}$

\section{Budgeting for Research: Indirect Costs}

The story of indirect costs begins with overhead. Any individual project or business of a larger organization necessarily excludes certain costs. For example, the costs of running a research lab do not directly support services necessary to its existence, such as the president's office, the animal care facility, and financial administration. The costs of the undergraduate college typically do not include the university admissions and financial aid offices or the classroom facilities and learning management system. One way to account for these overhead costs is to apportion them to the various projects and business lines that bring revenue into the university. For simplicity, one could say that in order for a university activity to "break even," it must cover not only its own costs but also its apportioned overheads.

University budgets cover many different activities, but one of the trickiest is externally funded research. The complexity derives from the fact that the funding largely comes in the form of grants. Other services-such as education or clinical care-are priced through tuition and fees that can be set at a level to cover all the associated overhead. But research is funded through grants, which pay the costs of the actual research activities. To support the associated overhead, many grant makers also pay for some portion of overhead costs. The intricacies of this model are substantial.

Awards generally include funds for "direct" and "indirect" costs (the latter of which are sometimes termed "F\&A" for facilities and administrative). Direct and indirect costs together comprise the real costs of conducting research at universities, "and eliminating either effectively impedes the ability to conduct quality research." ${ }^{17}$ If revenues are not secured to pay F\&A costs, the vast majority of the research activities at universities would not exist. Fundamentally, universities cannot implement research programs and activities if sponsors do not support the real costs of research infrastructure and necessary compliance measures.

\section{Indirect Costs and their Antagonists: A Brief History}

Prior to the 1930s almost all research at universities and within higher education was funded by either private foundations or philanthropic means. It was not until World War II that the federal government began to fund research at universities, "when national leaders recognized the importance of the contribution of basic and applied research to the war effort, comprehended its significance to national prosperity and strength, and deliberately established a means to

\footnotetext{
${ }^{16}$ Leroy W. Dubeck, "Beware Higher Ed's Newest Budget Twist," Thought \& Action (The NEA Higher Education Journal),1997, 8191.; Mallory Barnes and Kyle Clark, "Responsibility Center Management: The Good, The Bad, and The Ugly," Presentation at NACUBO, accessed August 31, 2020, https://www.nacubo.org//media/Nacubo/Documents/EventsandPrograms/2013PBF/Responsibility-Center-Management-Presentation. ashx.

17 "Excellence in Research: The Funding Model, F\&A Reimbursement, and Why the System Works," Council on Governmental Relations (COGR), April 2019, https://www.cogr.edu/sites/default/files/ExcellencelnResearch4 12 19 $0 . p d f$.
} 
maintain it." ${ }^{18}$ It is because of this federal funding that researchers at universities are able to perform necessary and fundamental applied and basic research that the government uses while also educating the next generation of researchers.

Indirect costs are a key component of federally funded research. The NIH, for example, has been paying indirect costs on federal grants for almost 70 years. In the 1950 os the NIH started paying indirect costs on grants, and at the beginning of this decade the initial rate was only 8 percent, but then rose to 20 percent of the total grant that could be used for indirect costs. Also in the 1950s, the Office of Management and Budget (OMB) put out Circular A-21, which dictates what costs can be covered by indirect funding. ${ }^{19}$ In 1965, the NIH started a negotiated indirect cost rate. A little over a decade later in 1979, modified total direct costs (MTDC), which is now a crucial variable in the calculation of indirect cost rates, came into the discussion. ${ }^{20}$ During the 1990s, increasing budget pressures coupled with allegations of serious cost accounting errors resulted in increased scrutiny of indirect costs at universities. ${ }^{21}$ In 1991, under a revised Circular A-21, restrictions were imposed which placed a cap on administrative costs at 26 percent of the MTDCs for universities and institutions of higher education only, excluding other organizations from this cap. ${ }^{22}$ This cap remains in place today despite the significantly increased administrative costs associated with conducting federally funded research. Many institutions are regularly above this 26 percent, forcing universities to cost share the unfunded project costs not covered by the sponsoring agency. ${ }^{23}$ While the Trump administration's plan to significantly cut indirect costs on federally funded research was swiftly eradicated, 24 it may suggest a broader need to reexamine the nature of how research is budgeted and funded.

\footnotetext{
${ }^{18}$ National Academies of Sciences, Engineering, and Medicine, Optimizing the Nation's Investment in Academic Research: A New Regulatory Framework for the 21st Century (Washington, DC: The National Academies Press, 2016), https://doi.org/10.17226/21824.

${ }^{19} \mathrm{OMB}$, "Circular A-21," Office of Management and Budget, May 10, 2004, https://obamawhitehouse.archives.gov/omb/circulars a021 2004/.

${ }^{20}$ Modified Total Direct Costs, or MTDC, are "the base to which F\&A (indirect costs) rates are applied." See Stanford University, "15.1 Facilities and Administrative (Indirect Cost) and Fringe Benefits Rates," DoResearch, 2020, https://doresearch.stanford.edu/policies/research-policy-handbook/financial-aspects-sponsored-projects-administration/facilitiesand-administrative-indirect-cost-and-fringe-benefits-rates). The OMB's Uniform Guidance document has defined this base for externally sponsored projects which are awarded after December 16, 2014 as follows: "MTDC means all direct salaries and wages, applicable fringe benefits, materials and supplies, services, travel, and up to the first $\$ 25,000$ of each subaward (regardless of the period of performance of the subawards under the award). MTDCs exclude equipment, capital expenditures, charges for patient care, rental costs, tuition remission, scholarships and fellowships, participant support costs and the portion of each subaward in excess of $\$ 25,000$. Other items may only be excluded when necessary to avoid a serious inequity in the distribution of indirect costs, and with the approval of the cognizant agency for indirect costs." Office of Management and Budget, "Uniform Administration Requirements, Cost Principles, and Audit Requirements for Federal Awards," Federal Register 78, no. 248, December 26, 2013, 78590-691, https://www.federalregister.gov/documents/2013/12/26/2013-30465/uniform-administrative-requirements-costprinciples-and-audit-requirements-for-federal-awards.

${ }^{21}$ One of the reasons the government capped administrative charges at 26 percent was due to the fact that they were finding "unallowable costs" in research grants.

${ }^{22}$ Meaning nonprofit research institutions, private industry, and other industries are not similarly subjected and restricted by this 26 percent cap.

${ }^{23}$ Sally Rockey (NIH), "Indirect Costs 101," YouTube, September 11, 2015, https://www.youtube.com/watch?v=1XvVibv2opQ\&t=260s.
}

${ }^{24}$ Andrew Kreighbaum, "Threat to University Research," Inside Higher Ed, April 3, 2017, https://www.insidehighered.com/news/2017/04/03/hhs-secretary-proposes-cutting-reimbursements-fund-university-based-research; 
To be sure, the indirect costs model still has its critics. Some argue that there is a substantial institutional inequity given that rich universities negotiate the best indirect rates. ${ }^{25}$ With this in mind some critics say that because institutions all have different indirect cost rates that these costs being tacked on to grants are "kind of cryptic." 26 Other analysis suggests that universities face a large sum of indirect costs for which they are not reimbursed. In fact, a 2020 report from the National Science Board (NSB) and the National Science Foundation (NSF) found that in 2018 the total unrecovered indirect costs totaled five billion dollars. ${ }^{27}$

\section{Defining Indirect Costs}

While performing federally sponsored research, universities incur a range of different costs which they otherwise would, ${ }^{28}$ both in the lead up process to accepting an award and while conducting research on that award. When a federal agency, such as the NIH, provides a grant to a university for an externally funded research project, a portion of the awarded money, most of the times around $65-75$ percent, ${ }^{29}$ is distributed directly to the research team. This money is known as a "direct cost." Direct costs are those that can be specifically identified and traced back to a particular project or activity and are deemed allowable under the federal agencies' sponsoring guidelines. The portion of the grant deemed as direct costs goes toward supporting researcher salaries, ${ }^{30}$ graduate students, supplies, and equipment needed to conduct research, and other such expenses.

The other portion of the funds from an external grant, normally around 25 - 33 percent, ${ }^{11}$ go towards "indirect costs" (IDC). ${ }^{32}$ Indirect costs are required and incurred in order for research,

Science News Staff, “What's in Trump's 2018 Budget Request for Science?” Science, May 23, 2017, https://doi.org/10.1126/science.aal1224; 12 Chief Research Officers, "Proposed Federal Policy Would Cripple University Research," Inside Higher Ed, July 21, 2017, https://www.insidehighered.com/views/2017/07/21/proposal-indirect-costs-would-put-researchuniversities-impossible-situation-essay; Jocelyn Kaiser, "NIH Plan to Reduce Overhead Payments Draws Fire," Science, June 2, 2017, https://doi.org/10.1126/science.aan6926.

${ }^{25}$ Andrew Kreighbaum, "Indirect Costs Back in the Crosshairs," Inside Higher Ed, June 2, 2017, https://www.insidehighered.com/news/2017/06/02/research-advocates-push-back-trump-proposal-dont-see-imminent-cutsuniversity.

${ }^{26}$ Anthony Cave, "Taking a Hard Look at University Research," Stanford Social Innovation Review, October 20, 2014, https://ssir.org/articles/entry/taking a hard look at university research.

${ }^{27}$ Josh Trapani and Michael T. Gibbons "Academic Research and Development," NSB-2020-2, National Science Board (NSB), Science \& Engineering Indicators, NSF, January 15, 2020, https://ncses.nsf.gov/pubs/nsb20202/academic-r-d-in-the-united-states.

${ }^{28}$ It is therefore the universities, not the federal government, that must assume the risk that comes along with building the necessary infrastructure and facilities to be able to support this type of research. This is often done in anticipation of university faculty, staff, and others successfully competing for federal research grants that the university will then be able to use to be reimbursed for a portion of the associated infrastructure costs.

${ }^{29}$ Stanford University, "Costs of Conducting Research," DoResearch, March 29, 2018, https://doresearch.stanford.edu/researchscholarship/costs-conducting-research.

${ }^{30}$ This includes the salaries of graduate students, postdocs, and researchers.

${ }^{31}$ Stanford University, "Costs of Conducting Research," DoResearch, March 29, 2018, https://doresearch.stanford.edu/researchscholarship/costs-conducting-research.

32 In 1996, the terminology changed from indirect costs over to F\&A costs. Karen A. Holbrook and Paul R. Sanberg, "Understanding the High Cost of Success in University Research," NCBI, Technology and Innovation, 15, no. 3, December 1, 2013, 269-80, https://doi.org/10.3727/194982413X13790020922068. 
or a common or joint activity to take place and, therefore unlike direct costs cannot be traced back to a specific project.

There are two components to indirect, or F\&A, costs. First there are the administrative costs of F\&A. The administrative costs include general items such as personnel, payroll, financial management, presidents, provost, etc. 33 They also include departmental administration coststhese are the services that are normally at the overarching university level-such as program and administrative costs at the college or department level within the university. These costs additionally cover sponsored research offices and the personnel required to support the essential administrative and regulatory compliance work that ensure grants are submitted, research training is conducted, and compliance with research requirements is being followed. They also cover some of the graduate student services (many graduate students are supported by externally funded federal research), so a proportion of student services costs can thus be built into the indirect cost rate. These administrative costs go towards supporting research projects at the university, but are not readily or specifically attributable to any particular research project. ${ }^{34}$ Instead, "F\&A is intended to reimburse (partially, at least) an institution for the real costs it expends to maintain the infrastructure that supports research conducted for the benefit of the federal government, the state, or the private sector (typically a foundation or industry)." 35 Finally, it is the administrative component of indirect costs that is capped at 26 percent of the MTDC. 36

The second component of indirect costs are the facilities and research infrastructure costs. This includes items such as building depreciation, interest on debt for certain buildings (that house federally funded researchers) that can be built in, equipment, capital improvements, equipment depreciation can also be built in (must be equipment not purchased with federal funds), maintenance of high tech labs which are used for cutting edge federally funded research, utilities used to heat and cool and keep the lights on in research facilities, disposal of hazardous waste materials, custodial cleaning, security, maintenance of the buildings, and other infrastructure that is deemed necessary to conduct federally funded research and comply with regulations.

Indirect costs (IDC) have the ability to be a very complex topic. It is therefore important to understand that they are actually reimbursements of costs which universities have in fact already paid for. While universities and federal sponsoring agencies do both contribute to the financial cost of maintaining research facilities, it is the university which will typically pay many of these expenses in advance, and then the federal agency sponsoring a project will reimburse

\footnotetext{
${ }^{33}$ It is important to note that indirect costs will not cover all of the expenses here, but they will cover a proportion of those individuals whose time and effort goes into the research enterprise.

34 "Primer on F\&A and Research Operating Costs," COGR, March 2017, https://www.cogr.edu/sites/default/files/1FA 2017 PRIMER.pdf.

${ }^{35}$ Karen A. Holbrook and Paul R. Sanberg, "Understanding the High Cost of Success in University Research," Technology and Innovation 15, no. 3 (December 1, 2013): 269-80, https://doi.org/10.3727/194982413X13790020922068.

${ }^{36} \mathrm{~F} \& A$ cost reimbursement for the administrative expenses is capped at 26 percent, meaning that anything beyond 26 percent is a cost that the university must incur. The administrative expenses at most research institutions tends to exceed the 26 percent federal administrative cap. Any of the additional administrative costs associated with sponsored research over the 26 percent cap do not increase $F \& A$ cost rates and these costs are not reimbursed.
} 
said university for part of these expenses. 37 The research enterprise is what it is today partly because of those reimbursements, which have "helped US colleges and universities build and support the required research infrastructure." 38

\section{Calculating the Federal Indirect Cost Rates}

The agreed upon indirect cost rate is what defines the reimbursement of F\&A costs by way of a federally negotiated rate. Currently each college and university negotiates its own indirect cost rate with the federal government every few years. 39 These overhead rates will differ across institutions for many reasons, a few of them being geographic location-intuitively costs are higher in urban areas-and because research expenses will be different across institutions.

In order to determine the level of reimbursement, or indirect cost rate, universities and the federal government must periodically evaluate all of the shared costs of research and then work together to determine an appropriate federal share. For colleges and universities in the US-as well as non-profits, hospitals, and state and local governments-indirect cost rates are negotiated by cognizant agencies rather than by the NIH or NSF. For example, rates could be negotiated with cognizant agencies such as the Department of Health and Human Services (HHS) division of cost allocation or the Department of Defense's Office of Naval Research (DOD). Whomever the university is receiving most of their funds from will negotiate the rate..$^{40}$

Institutions are required to separate out the costs of non-research activities from research activities, which is very important because an agency, such as the NIH, will negotiate based on what the space and the administration costs are associated with research activities. This is what the NIH and other federal agencies will pay for. This separation process is the tricky part, and it

\footnotetext{
${ }^{37}$ Sponsors do not cover the full costs of conducting research that they support. The remaining unfunded costs of research are most often cross subsidized through the university, school, or department contributions. Therefore, universities also have costs associated with externally funded research. University contributions, for the most part, include some of the following: research buildings and laboratories, start-up funds for faculty that support early career research and lab activities, research administration staff, administrative and financial management tracking systems, investment in physical and digital library collections and digital repository of research data and results, university mandatory cost sharing which is required by some federal sponsors, and all costs incurred above the 26 percent cap mandated by the federal government for the administrative component of F\&A costs. Stanford University, "Costs of Conducting Research," DoResearch, March 29, 2018, https://doresearch.stanford.edu/researchscholarship/costs-conducting-research.

38 "Frequently Asked Questions about Facilities and Administrative (F\&A) Costs of Federally Sponsored University Research," Association of American Universities, May 16, 2017, https://www.aau.edu/key-issues/frequently-asked-questions-about-facilitiesand-administrative-fa-costs-federally.

${ }^{39} \mathrm{~F} \& A$ rates are negotiated with the federal government, reviewed by the rate setting cognizant agency, and finally negotiated between the university and the rate-setting cognizant agency. This process follows the rule established by the OMB, more specifically defined in 2 CFR part 200. See Office of Management and Budget, "Uniform Administration Requirements, Cost Principles, and Audit Requirements for Federal Awards," Federal Register 78, no. 248 (December 26, 2013): 78590-691, https://www.federalregister.gov/documents/2013/12/26/2013-30465/uniform-administrative-requirements-cost-principles-and-auditrequirements-for-federal-awards. For non-federally funded research grants, sponsors are not expected to comply with these federal accounting rules and regulations. However, it is important to keep in mind that research institutions are never fully reimbursed for their F\&A costs; this is "defined" in institutions F\&A cost rates.

${ }^{40}$ National Institutes of Health (NIH), "Understanding Indirect Costs," NIAID Funding News, April 19, 2017, https://www.niaid.nih.gov/grants-contracts/understanding-indirect-costs.
} 
is conducted to ensure that reimbursements on federally sponsored research grants for both direct and indirect costs are solely going towards supporting the conduct of research.

This calculation is quite simple and involves two components. First, you begin with the F\&A costs (the pool) that are related to research that are going to be recovered by the application on an indirect cost rate. Next you factor in the direct research costs (the base) which are used to determine the rate; the direct cost is what will in turn determine the indirect cost reimbursements to an institution on funded research projects. Therefore, to find the rate the equation is:

\section{F\&A costs [the pool] $\div$ Direct Research costs [the base] $=$ Rate}

For example, if the F\&A costs were $\$ 600,000$ and the direct costs were $\$ 1,200,000$ then the indirect cost rate would be 50 percent. ${ }^{41}$

While the process to negotiate a rate is complicated, once negotiated that rate stays in place for up to four years. Once a university has established a rate it then applies this rate to all of the federally sponsored research received, regardless of funding agency or discipline. This means that any single research grant can be highly profitable or loss making, since the indirect cost rate is calculated as an average across the entire university research enterprise. ${ }^{2}$

To determine the total award amount for a project, the university first calculates the project costs. Then, certain direct expenses such as for equipment, capital expenditures, charges for patient care, scholarships, and fellowships are removed to create a base award calculation (the MTDC). The indirect cost rate is then applied to this base to calculate the eligible indirect costs. Finally, the base rate, the ineligible direct expenses, and the applied indirect costs are added together to determine the total award amount. 43 The consequence of this model is that the

\footnotetext{
${ }^{41}$ At this point in the calculation process it is important to understand that this 50 percent rate does not mean that 50 percent of the overall grant funding will be allocated to indirect costs. Sally Rockey (NIH), "Indirect Costs 101," YouTube, September 11, 2015, https://www.youtube.com/watch?v=1XvVibv2opQ\&t=260s.

${ }^{42}$ For an example of some university rates see the following: Stanford University, "Rates," DoResearch, November 3, 2020, https://doresearch.stanford.edu/research-administration/proposal-and-award-lifecycle/rates; University of Washington Office of Research, "Institutional Facts and Rates," Research University of Washington, 2020, https://www.washington.edu/research/institutional-facts-and-rates/\#fa-rates-table.

${ }^{43}$ To demonstrate how research award amounts are calculated we give the following example. If a researcher at a university requests $\$ 300,000$ for a project and $\$ 50,000$ of that sum is for equipment that amount must then be subtracted from the direct costs awarded as that equipment is not subject to indirect costs. This leaves $\$ 250,000$ for a MTDC base.

Direct Costs Awarded - Equipment $=$ MTDC Base

$\$ 300,000-\$ 50,000=\$ 250,000$

Following this simple calculation, the indirect costs are then applied to the MTDC base. Note that the IDC equals the negotiated IDC rate times the MTDCs. So, if we take the sample negotiated rate calculated in the section above, 50 percent, that would then be multiplied by the MTDC base.

Negotiated IDC Rate $\times$ MTDC Base = IDC Costs

$50 \% \times \$ 250,000=\$ 125,000$

To figure out the total award amount the federal agency will then take the direct cost and add it to the IDC costs.

Direct Cost $+I D C$ Costs $=$ Total Award Amount
} 
indirect cost rate can appear misleadingly high, given the important categories of expenses that are ineligible.

\section{Implications on Research?}

At the highest level, the federal funding approach covers a substantial enough share of the university's indirect costs to keep universities in the research business. But there are also some unintended consequences of the overall funder models.

In some institutions, especially those with distributed revenue control budget models, indirect cost revenues, just like direct cost revenues, are returned to the school or department that originated the grant. Since federal funding agencies pay a flat indirect cost rate across the university, this can result in some strange dynamics depending on how departments are organized. For example, in a school that has humanities and social sciences only, with no laboratory or field sciences, federal grants can be seen as being tremendously "profitable." However, a federal grant to the natural, biological, or life sciences within a university will likely not cover costs much less generate a surplus.

The federal government is the largest funder of academic research. As of 2018 nonprofit organizations provided about 7 percent of academic R\&D funding while businesses (or industry) made up around 6 percent, state and local governments around 5 percent, and other sources comprised only around 3 percent. 44 Historically, many foundations view their research grant funding as capital that supplements research that scientists are already in the process of conducting. In fact, universities themselves are the second largest funders of academic research.

To avoid becoming too dependent on self-funding, institutions will sometimes act to steer away from funding sources that do not cover the full costs of research including overhead. Sometimes this comes by charging a "tax" on all grants that turns those without overhead into substantial losses. These approaches, while they may seem strange when applied to any single grant that will increase research revenues, are taken to avoid tipping the scales towards unsustainable losses. This in turn helps institutions minimize the amount of cost sharing that is necessary and decrease potential losses from funded research.

$\$ 300,000+\$ 125,000=\$ 425,000$

It is important to note in this example that even though the hypothetical institution used has a 50 percent IDC rate, the indirect costs only comprise about 29 percent of the total funds being awarded. It is very typical for federal agencies, such as the $\mathrm{NIH}$, to award around less than a third of the total award fund for indirect costs.

44 Josh Trapani and Michael T. Gibbons "Academic Research and Development," NSB-2020-2, National Science Board (NSB), Science \& Engineering Indicators, NSF, January 15, 2020, https://ncses.nsf.gov/pubs/nsb20202/academic-r-d-in-the-united-states. 